\title{
Research on the Technical and Economic Problems of the Development of Distributed Generation
}

\author{
Chenhao Niu \\ Information Construction and Management Office of \\ the North China Electric Power University \\ Beijing, China \\ 405506114 @qq.com
}

\author{
Bingjie Li \\ School of Economics and Management of North China \\ Electric Power University \\ Beijing, China \\ crazyjennylee@163.com \\ * Corresponding Author
}

\begin{abstract}
Recently, the proportion of distributed generation in the power system is growing with the increasing development and of distributed generation technologies. The application of distributed generation brings many benefits to the grid, such as improving power quality and peak load and helping achieve optimal allocation of resources and so on. From the perspective of sustainable development, the national energy strategy, reduced environmental pollution, and construction a harmonious society, the development of distributed generation technology has become an inevitable choice. In view of this situation, this paper describes the significance of the development of distributed power sources, and analyzes the characteristics of distributed power from investment, transmission losses, security of supply and reliability, demand of special areas and environmental pollution. It raises the technical and economic issues of the development of distributed generation of technology, economy, market and energy supply. Finally, for the existing practical difficulties in the project research, it provides references for the development of distributed power from state management, technological development, social mobilization and other aspects of the question of how to further develop the distributed power to the development of the distributed generation.
\end{abstract}

Keywords-Distributed Generation; Clean Energy; Technical Economy; Energy Supply

\section{INTRODUCTION}

With the diversification of human demand for energy supply and the increase of environmental protection requirements, the distributed generation is becoming one of the future directions of the world's electric power development. The applications of distributed generation in China are in its infancy, the development is relatively slow, and some obstacles are confronted. In order to better promote the development of distributed generation and strengthen its technical and economic research of the problem, it becomes more important to put forward relevant proposals of developments.

Recently, the proportion of distributed generation in the power system is growing because of the increasing development and the distributed generation technologies. The application of distributed generation brings many benefits to the grid, such as improving power quality and peak load and helpingg achieve optimal allocation of resources and so on. From point of view of sustainable development, the national energy strategy, reduced environmental pollution and the construction of a harmonious society, the development of distributed generation technology has become an inevitable choice.

Firstly, the paper described the development of distributed generation, and then proposed the technical and economic problems of the development of distributed generation from four aspects of technical, economic, market and energy supply. For the currently existed practical difficulties, the paper proposed policy proposals of how to further develop distributed generation for related work reference.

\section{THE SIGNIFICANCE OF THE DEVELOPMENT OF DISTRIBUTED GENERATION}

The development of distributed power supply has farreaching significances, specifically summarized in the following Fig. 1:

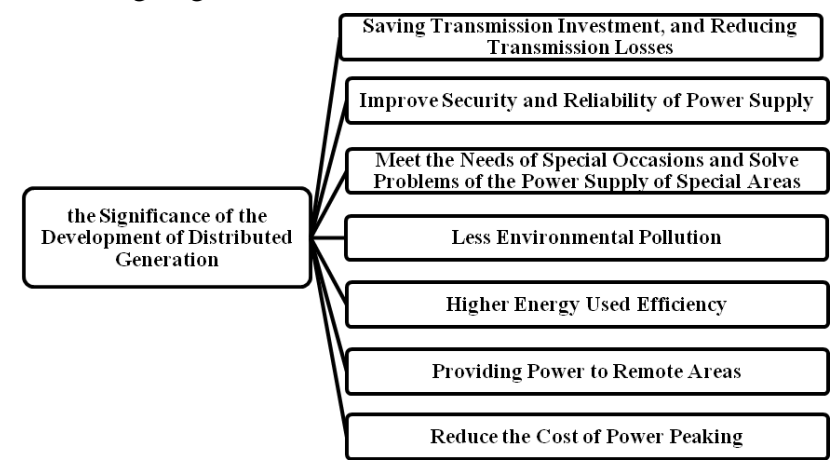

Figure 1. the Significance of the Development of Distributed Generation .

\section{A. Saving Transmission Investment, and Reducing Transmission Losses}

The capacity and footprint of the distributed generation are small, and the initial investment is low. At the same time, the position of distributed generation system is usually close to the power demand side, there is no longdistance transmission line losses caused by high energy 
efficiency. For terminal users, they can flexibly choose the way of energy services to adapt to different situations. In China, it is difficult to lay large-scale grid in the remote western region. In some areas, users are decentralized, and laying the grid has poor cost-effectiveness. For these areas, you can choose to develop distributed generation. In addition, distributed generation can be effectively utilized waste heat and pressure of large-scale power plants and other waste resources, and the combustible waste gases can be effectively used to improve energy efficiency, while also protecting the environment.

\section{B. Improve Security and Reliability of Power Supply}

Distributed generation system is placed directly next to the user, which is independent of the power plant, and the user can control. If parallel operating with the large grid, it can effectively reduce the impact of power load fluctuations on the power grid, and partially eliminate the grid overload and congestion which will improve margin transmission grid, and reduce the possibility of a serious accident [1]. For power users, when the utility grid fails, the user can cut off contact with the grid of their own to avoid being affected. When the distributed generation fails, the large power grid also provides support for users of electricity demand.

\section{Meet the Needs of Special Occasions and Solve Problems of the Power Supply of Special Areas}

As the power demands are diverse, some special areas have special demand for electricity, and the power grid is difficult to meet all the specific requirements, but distributed generation system is able to more effectively address these special circumstances, such as, decentralized power users, unable to set up the grid in remote areas or mountainous west, hospitals, banks, other particular user with high demands for energy stability, and the user needs a variety of energy supply. The advantages of distributed generation are less distribution losses, more flexible operation, and can be remotely control and relatively reliable.

\section{Less Environmental Pollution}

The fuel distributed generation used is mostly clean energy, which can reduce greenhouse gas emissions and solid waste. In addition, the electromagnetic pollution and noise pollution are also low.

\section{E. Higher Energy Used Efficiency}

On the one hand, if to meet the supply of heat, hot water, air-conditioning and other energy through the power supply, it often results in some loss of energy. Distributed generation supply system can be recycled or organic integrated way to use energy, and meet different energy demands of users. On the other hand, under the way of large and centralized power plants, the comprehensive energy utilization efficiency of end users is only $30 \%$ $47 \%$, but because there is no transmission line losses, distributed the comprehensive energy efficiency of end users of power supply system can be achieved more than $80 \%$, almost $100 \%$ higher than a centralized power generation.

\section{F. Providing Power to Remote Areas}

Renewable energy distribution is more dispersed, and it is difficult to focus its use. The distributed generation system can effectively use decentralized energy supply to remote areas.

\section{G. Reduce the Cost of Power Peaking}

Because the system involved in less thermal power units than ordinary, the operation and workflow of distributed generation device is relatively simple. When the electricity load changes, the response speed of distributed systems is rapid, and lower load, startup and shutdown speed are relatively quickly. It can effectively cooperate with scheduling systems when peaking in the power system, and even realize full automation peaking which can improve the efficiency and reduce costs. The client can also reduce the use of distributed generation grid for summer cooling and winter heating to a certain extent, which can reduce supply pressure and spare capacity of large-scale unit to reduce electricity fixed investment. It will help power industry toward a more efficient and more economical industrial road.

\section{DEVELOPMENT OF TECHNICAL AND ECONOMIC PROBLEMS IN DISTRIBUTED GENERATION}

As the general distributed generation is very small, and the generation efficiency is low, in addition, the personnel requirements of operation and maintenance of distributed generation are relatively high, so its price is relatively higher. Technical and economic problems of the development of distributed generation supply are mainly reflected in the following four points as Table I:

TABLE I. FOUR POINTS

\begin{tabular}{|c|c|c|c|c|}
\hline No. & $\mathbf{1}$ & $\mathbf{2}$ & $\mathbf{3}$ & $\mathbf{4}$ \\
\hline & Technology & Economy & Markets & Energy Supply \\
\hline
\end{tabular}

\section{A. Technology}

The access of distributed generation to the distribution network has changed the grid structure, flow and the voltage regulation require ments, so the power quality will also be affected. First of all, due to the different ways of distributed generation systems, frequency and current vary greatly, so it is hard to synchronously operate the power generation equipment. Secondly, if the mounting position of DG inappropriate, or select the device capacity and access equipment inappropriately, it may cause the original protection device failure, malfunction, reducing the stability of power system operation and reliable of distributed generation equipment connected to the grid which may reduce the stability and reliability of power system operation [2]. Power quality problems will affect the safe use of electrical equipment.

If access distributed generation to distribution network, it could lead to the protection system of the existing distribution network not promptly removing the main line failure and the system voltage may deviate from the normal range, so that to impact on the grid protection.

\section{B. Economy}

The environmental and social benefits of distributed generation are obvious, but the benefit in this regard is not 
good quantification. On the other hand, due to the instability of distributed generation, the grid is required to provide supported services. Its construction cost of spare capacity in the economy analysis of actual project is difficult to define, so that to cause a certain degree of difficulty for project evaluation. The distributed generation project analyses of existing indicator system are quite different, and it's difficult to horizontal comparison between projects, so that there is a big problem to carry out economic evaluation of such projects.

In addition, as the initial investment of distributed generation systems is large, and the lack of profitability, less private investment lead to slow development of distributed generation. It need the government to put out policy support, giving certain subsidies. Although subsidies can improve the economy, it also requires the government to pay a certain economic support.

\section{Markets}

The access of distributed generation systems to the utility grid increased the complexity of the electricity market transactions. For example, how to calculate the costs of grid connection of distributed generation system, high costs of grid to provide backup and price of selling surplus electricity to the power grid become the discussed focus of all countries of the world in the development of distributed generation systems [3]. In the reform and development of current electricity market, it has become a important technical and economic problem of emerging issues.

\section{Energy Supply}

China needs to attach great importance to the supply of natural gas. The construction of natural gas distributed generation systems for the natural gas supply system had a considerable impact, such as the supply, supply price and supply time of natural gas. Therefore, in order to ensure a stable supply of natural gas, the construction of natural gas distributed generation system has become an urgent problem. It is the cause of what researchers must consider when developing them.

\section{DEVELOPMENT STRATEGIES}

The below Fig. 2 describes the development of distributed generation from four strategies:

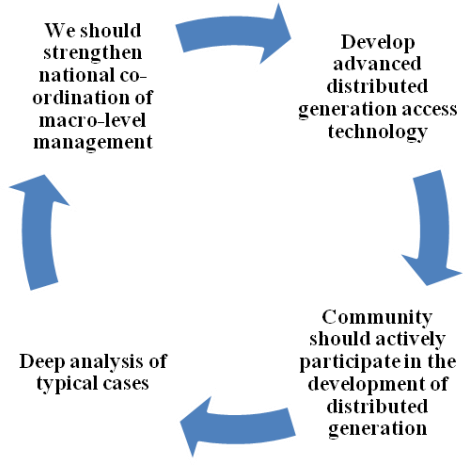

Figure 2. Development strategies.

\section{A. We should strengthen national co-ordination of macro-level management}

On one hand, the state should develop a reasonable strategy, put the development of distributed generation into relevant government planning, give preferential subsidies, reduce operating costs, and encourage the development of distributed generation projects. On the other hand, it should improve laws and regulations at all levels, and establish distribution power project evaluation criteria to unify electricity metering and settlement of electricity in the electricity market, which has given the active guidance to the development of distributed generation.

\section{B. Develop advanced distributed generation access technology}

It is necessary to take efforts to develop the advanced distributed generation access technology, improve the selfoptimizing control level of the power grid and micro-grid, strive to improve their distributed generation efficiency and reliability, and improve primary energy mining technology and new energy technologies of DG.

\section{Community should actively participate in the development of distributed generation}

The community should be targeted for demonstration, planning, investment and construction and encouraging energy suppliers, power companies, power users and investors to actively participate in distributed generation projects. The depth of cooperation to create favorable for the development of distributed generation surroundings.

\section{Deep analysis of typical cases}

It is important to strengthen information technological work, research development of DG at home and abroad, carry out typical case analysis, drawing excellent case management experience, improving power forecasting level of distributed power sources, researching on development model of intelligent micro-grid and promoting the healthy development distributed generation project development of.

\section{REFERENCES}

[1] Ran Peng, Zhang Shufang, Guo Jianglong, Maoning. The Research Status and Prospect of Distributed Energy Systems[A]. Thermal Power Generation, 2005(03):1-3.

[2] He Xinqun. The Impact of Distributed Generation on Distribution System[J]. Hu Nan Water Resources and Hydropower,2009(3):9091.

[3] Wang Xinmao. Discussion on Development-related Issues of Distributed Energy Systems[C]. Technical and Economic Power, 2007(6):6-8.

[4] Lin Shiping. Research on Couping Characteristics and Integrated Optimization Model of Energy and Environment Based on DES[D]. Wuhan University, Dec, 2011.

[5] He Yuan. Analysis and Optimization of Distributed Energy System[D]. Tianjin University, July, 2007.

[6] Chen Anwei. Research on the Technical Economic Problems of the Smart Grid[D], Chongqing University, Oct, 2012.

[7] Zhu Xiaojun, Niu Xiaodan, Zhang Chao, Qi Shifeng, Wang Cheng. Natural Gas Distributed Energy System Technology Economy Comprehensive Evaluation of Research and Application[J]. Science Technology and Industry, 2014(04),14, 60-64.

[8] Wu Qiwei. Natural gas distributed energy and its application[J]. Application, 2012(04), 24-30. 
[9] Wang Yan. Research on Strategies and Programs of the DeveloPment of Distributed Energy System of Heilongiiang Province[D]. North China Electric Power University, June,2011.
[10] Song Xiaohua. Energy-Conservation Route of Power Generation Industry based on Low- Carbon Economy[D]. North China Electric Power University, June, 2012. 